\title{
Biosolids Soil Application: Why a New Special on an Old Issue?
}

\author{
Silvana I. Torri, ${ }^{1}$ Rodrigo Studart Corrêa, ${ }^{2}$ Giancarlo Renella, ${ }^{3}$ Alejandro Valdecantos, ${ }^{4}$ \\ and Leonid Perelomov ${ }^{5}$
}

${ }^{1}$ Department of Natural Resources and Environment, School of Agriculture, University of Buenos Aires, Avenue San Martin 4453, Buenos Aires 1417 DSE, Argentina

${ }^{2}$ Department of Ecology, University of Brasilia, Campus Darcy Ribeiro, Caixa Postal 04.401, 70910-970 Brasilia, DF, Brazil

${ }^{3}$ Department of Plant, Soil and Environmental Sciences, University of Florence, P. le delle Cascine 28, 50144 Florence, Italy

${ }^{4}$ Foundation for Environmental Studies Centre of the Mediterranean (CEAM), C/Charles R. Darwin 14, Parque Tecnológico, 46980 Paterna, Spain

${ }^{5}$ Department of Biology and Medicine, Tula State University, Lenin Avenue 92, Tula 300012, Russia

Correspondence should be addressed to Silvana Torri, torri@agro.uba.ar

Received 3 September 2012; Accepted 3 September 2012

Copyright (C) 2012 Silvana Torri et al. This is an open access article distributed under the Creative Commons Attribution License, which permits unrestricted use, distribution, and reproduction in any medium, provided the original work is properly cited.

\section{Introduction}

The term biosolids was introduced in the early 1990s by the Water Environment Federation to define the solid, semisolid, or liquid residues generated during primary, secondary, or advanced treatment of domestic and industrial sanitary sewage sludge through one or more controlled processes that reduce pathogens and attractiveness to vectors. Although the term biosolids is related to the definition of sewage sludge, it only refers to the portion of sewage sludge that has undergone adequate treatment to permit its land application, such as anaerobic and aerobic digestion, composting, thermal or air drying, and alkaline stabilization with additives such as lime or cement kiln dust.

An extensive body of scientific evidence has recognized that biosolids should not be seen just as a waste, but could be beneficially recycled as a soil conditioner because of its stable organic matter matrix. The fertilizer value of biosolids has also been extensively researched (e.g., [1, 2]). Consequently, a worldwide massive biosolids' use as soil conditioner and fertilizer arose in the early 1900s [3]. Whilst recognising its significant value as a resource, recycling sewage sludge to agricultural land requires a careful management to avoid potential negative impacts on the environment from chemical contaminants. Among them, potentially toxic elements (PTE) and organic chemicals are usually transferred to biosolids during waste water treatment process. As a consequence, in the 1990s there was pressure in some European countries to ban the use of biosolids for agricultural use.
Austria, Sweden, and Switzerland, among others, introduced the ban. Other countries developed strict sanitary and environmental regulations to ensure biosolids safe use for land application (e.g., European Directive 86/278/EEC, US EPA's Part 503). Very importantly, all the EU acts have been inspired by the fact that land application of biosolids improves soil fertility and has an important role in closing nutrient cycles, especially phosphorous $(\mathrm{P})$. In addition to these benefits, land application of biosolids has the advantage of increasing carbon (C) sequestration and thus contributes to $\mathrm{C}$ mitigation measures to meet European climate change commitments under the Kyoto Protocol [4, 5]. For this reason, the restoration of degraded sites, commonly showing low soil fertility and poor physical properties, is a raising option as its final disposal [6].

\section{Biosolids Soil Application: Agronomic and Environmental Implications}

In the last decades, the cooperative activity of research institutions, industry, and authorities have led to the development of different technologies that dramatically improved biosolids quality to abate harmful organic and inorganic pollutants, together with pathogens control, so as to reach the highest certification degree for biosolids land application. The absence of manifest adverse effects on soils, crops, and humans is probably key point leading to a sustainable use of sludge and to its public acceptance. We believe that this 
special issue, focused on the study of the potential benefits and risks related to land application of biosolids, though not exhaustive, sheds new light on this crucial topic.

The review made by Q. Lu et al. provides information on recent research progresses and regulation efforts regarding land application of biosolids in the USA, including forms and types, nutrient value, and environmental and health concerns.

S. Torri and R. S. Correa deeply reviewed the different aspects that control downward movement of biosolids-borne potentially toxic elements (PTEs) in soils. The paper describes the key issues of the possible problems generated by this practice related to cadmium, copper, chromium, lead, nickel, and zinc vertical mobilization. Soil pH, soil texture, and increased soil-dissolved organic matter concentration as a result of land application of biosolids may lead to the formation of organo-PTEs complexes that may result in a substantial movement of PTEs into subsoil horizons, with the risk of ground water contamination.

Controlling plant pests is a relevant issue of potential use of organic amendments. S. Kouki and colleagues tested, in vitro and in vivo, the effectiveness of a compost of vegetable waste and Posidonia oceanica mixture (VPC) in controlling Fusarium wilt in tomato. They found a significant reduction of damping-off incidence on tomato plants using the VPC amendment and it may be attributed to the effect of polyphenols and other chemical compounds. The study showed that microorganisms isolated from compost are able to suppress plant disease. Some VPC bacteria (Bacillus, Burkholderia, and Pseudomonas) play an antimicrobial activity against Fusarium, probably due to the antibiotics secreted by bacteria, which may confer fungicidal properties.

The paper of C. A. Christofoletti et al. evaluated the possible toxic effects of biosolids sample, under laboratory conditions, using diplopods (Rhinocricus padbergi) and plants (Allium cepa) as test organisms. The data obtained demonstrated that biosolids raw sample had genotoxic potential for Allium cepa root tip cells. In the diplopods exposed to biosolids sample, epithelium disorganization in the midgut and a reduction of the volume of the hepatic cells were observed after 7 days of exposure. After 30 days, the animals are still showing a reduction of the volume of the hepatic cells, but in minor intensity. Allium cepa analysis showed genotoxicity, but this effect was reduced after 30 days of bioprocessing by diplopods.

N. E. Hansen et al. compared composted municipal biosolids and dairy manure products to stabilize roadside soils. They reported that the greatest total and soluble phosphorus and total nitrogen losses in runoff water occurred from soils where the compost and woodchip mix were applied. In contrast, nitrate-nitrogen losses in runoff were similar when compost was incorporated in the soil or applied in the woodchip mix. Compost source affected the nutrient losses in runoff. While the composted municipal biosolids added greater nutrient loads to the soil, less nutrient loss in runoff occurred.

A. Branzini et al. studied the speciation of $\mathrm{Cr}, \mathrm{Cu}$, and $\mathrm{Zn}$ in soils amended or not with compost and highlighted how biosolids application was able to change metal speciation. The complex soil-metal chemistry system suggests that the application of a single organic amendment may not effectively reduce the solubility of these elements because of dissimilar chemical properties. Therefore, different organic/inorganic combinations have to be considered.

S. Shaheen et al. examined the role of different organic and inorganic amendments for stabilizing industrial and domestic biosolids in two contrasted types of soils, as well as the effect of the time of incubation and mixing rate. In general, stabilized products increased soil Olsen-P and reduced the availability of copper and zinc, especially bentonite, sugar beet factory lime, coal fly ash, rice straw, and water hyacinth.

The responses of peanut plants to soil application of $\mathrm{Pb}$ contaminated sludge in comparison to mineral fertilization were evaluated by F. Camilotti et al. The outcome from this greenhouse experiment showed that the used sludge worked as $\mathrm{P}$ source to young peanut plants and that high $\mathrm{Pb}$ concentrations in the sludge did affect the overall plant growth. However, the increased $\mathrm{Pb}$ solubilisation, likely induced by the plant root activity, along with the higher $\mathrm{Pb}$ content in plant shoots and pod husks, may pose risks to human health as peanut kernels and their products may mix up with husk fragments, the industrial processing of peanuts.

Taking into account the fact that land application of biosolids should nowadays meet the international protocols of pedosphere, atmosphere, hydrosphere, and biodiversity protection, there are a number of emerging issues that require consideration and attention.

\section{Needs and Gaps}

\subsection{Needs}

Wider Comparison of Effects of Sludge Treatments on Soil Properties and Functions. Composting and thermal drying are among the commonly used techniques for achieving concentration, sanitation, and stabilization of sludge. However, it is well established that different sludge after treatments will lead to different effects on soil properties and on soil microbial activity. Generally, composting has lower but more persistent stimulatory effects than raw of that thermally died sludge $[7,8]$. This is likely due to treatmentinduced changes in the organic matter degradability, but it might also indicate the presence and release of toxic substances from the sludge matrix. Moreover, a subject still not fully investigate is the potential of selected biosolids for maintenance and protection of soils under short rotation forestry for biomass production, where fast nutrient removal needs to be balanced.

Monitoring Persistent Dangerous Substances Such as Potentially Trace Elements or Organic Pollutants, together with the Identification of New Classes of Micropollutants. For example, nanomaterials present in wastewater or intentionally used for biosolids stabilization [9] likely accumulate in biosolids at concentrations in the order of $\mathrm{mg} \mathrm{kg}^{-1}$. These nanomaterials may negatively impact plants, soil microorganisms or soil ecological functions. It is noteworthy to underline that 
most of the use and release of nanoparticles are not fully regulated yet.

Monitoring Pathogens Such as Prions Which May Be Present in the Original Biosolids and Persist in Soils. While the biomolecular of methods for the screening of pathogens in wastewater, sludge, and soil are well established, a specificaspect of pathogens in soils is their viable but noncultivable (VBNC) status, induced by the paucity of nutrient and low water availability in soils. Because the VBNC phenomenon has been described also for pathogenic bacteria [10], more studies are surely needed to better understand the potential virulence of human pathogens during their transit from the sludge matrix to the soil environment. From this point of view, new potent bio-molecular approaches such as proteomics may be used for studying the functional structure of the different biosolids, following the example of the pioneering study of Ehlers and Cloete [11] and Wilmes and Bond [12].

\subsection{Gaps}

Effectiveness of Recovery of Degraded Marginal Lands through Biosolid Amendments, with Lower Nutrient Levels, and the Construction of Technosols from Mine Tailings through Biosolids amendment: from this point of view there is scarce published scientific evidence on the speed and direction of pedogenesis.

Improvement of Phosphorus Recycling and Availability on the Biosolids. Phosphate recycling is of great importance for primary productions not only because of its relatively low availability in soils, but also because at the current rate of extraction and use, the estimated P reserves may run out in 100-200 years [13].

Biosolids Mining. Biosolids incorporation into soils generally trigs a potent metabolic response of soil microbial communities, not fully explained by the nutrient loads. It has been reported that organic wastes may contain bioactive molecules such as phytohormone precursors [14], and that the presence of trace amounts of such substances stimulates soil microbial activity [15]. Therefore, more research is needed on biosolids biological and chemical prospection for the search of biologically active substances, which may act as extracellular signals for gene activation or signal molecules within the soil microbial communities, which might be concentrated and used for improving the beneficial effects of biosolids in agricultural production.

\section{Silvana Torri \\ Rodrigo Studart Corrêa Giancarlo Renella \\ Alejandro Valdecantos \\ Leonid Perelomov}

[3] R. Frank, "The use of biosolids from wastewater treatment plants in agriculture," Environmental Management, vol. 9, pp. 165-169, 1998.

[4] P. Smith, K. W. Goulding, K. A. Smith et al., "Enhancing the carbon sink in European agricultural soils: including trace gas fluxes in estimates of carbon mitigation potential," Nutrient Cycling in Agroecosystems, vol. 60, no. 1-3, pp. 237-252, 2001.

[5] S. Torri and R. Lavado, "Carbon sequestration through the use of biosolids in soils of the Pampas region, Argentina," in Environmental Management: Systems, Sustainability and Current Issues, H. C. Dupont, Ed., Nova Science Publishers, Hauppauge, NY, USA, 2011.

[6] R. Lal, "Soil carbon sequestration in China through agricultural intensification, and restoration of degraded and desertified ecosystems," Land Degradation \& Development, vol. 13, no. 6, pp. 469-478, 2002.

[7] M. P. Bernal, M. A. Sánchez-Monedero, C. Paredes, and A. Roig, "Carbon mineralization from organic wastes at different composting stages during their incubation with soil," Agriculture, Ecosystems \& Environment, vol. 69, no. 3, pp. 175-189, 1998.

[8] W. A. Ramírez, X. Domene, O. Ortiz, and J. M. Alcañiz, "Toxic effects of digested, composted and thermally-dried sewage sludge on three plants," Bioresource Technology, vol. 99, no. 15, pp. 7168-7175, 2008.

[9] X. Q. Li, D. G. Brown, and W. X. Zhang, "Stabilization of biosolids with nanoscale zero-valent iron (nZVI)," Journal of Nanoparticle Research, vol. 9, no. 2, pp. 233-243, 2007.

[10] J. D. Oliver, "Recent findings on the viable but nonculturable state in pathogenic bacteria," FEMS Microbiology Reviews, vol. 34 , no. 4, pp. 415-425, 2010.

[11] M. M. Ehlers and T. E. Cloete, "Comparing the protein profiles of 21 different activated sludge systems after SDS-PAGE," Water Research, vol. 33, no. 5, pp. 1181-1186, 1999.

[12] P. Wilmes and P. L. Bond, "The application of two-dimensional polyacrylamide gel electrophoresis and downstream analyses to a mixed community of prokaryotic microorganisms," Environmental Microbiology, vol. 6, no. 9, pp. 911-920, 2004.

[13] J. T. Sims and A. N. Sharpley, "Strategies for the sustainable management of phosphorus," in Phosphorus: Agriculture and the Environment, J. T. Sims and A. N. Sharpley, Eds., American Society of Agronomy, Madison, Wis, USA, 2005.

[14] I. A. Arkhipchenko, A. I. Shaposhnikov, and L. V. Kravchenko, "Tryptophan concentration of animal wastes and organic fertilizers," Applied Soil Ecology, vol. 34, no. 1, pp. 62-64, 2006.

[15] G. Renella, L. Landi, J. M. Garcia Mina, L. Giagnoni, and P. Nannipieri, "Microbial and hydrolase activity after release of indoleacetic acid and ethylene-polyamine precursors by a model root surface," Applied Soil Ecology, vol. 47, no. 2, pp. 106-110, 2011.

\section{References}

[1] E. G. Coker, "The value of liquid digested sewage sludge," Journal of Agricultural Science, vol. 67, pp. 91-97, 1966.

[2] H. A. Elliott and G. A. O'Connor, "Phosphorus management for sustainable biosolids recycling in the United States," Soil Biology and Biochemistry, vol. 39, no. 6, pp. 1318-1327, 2007. 

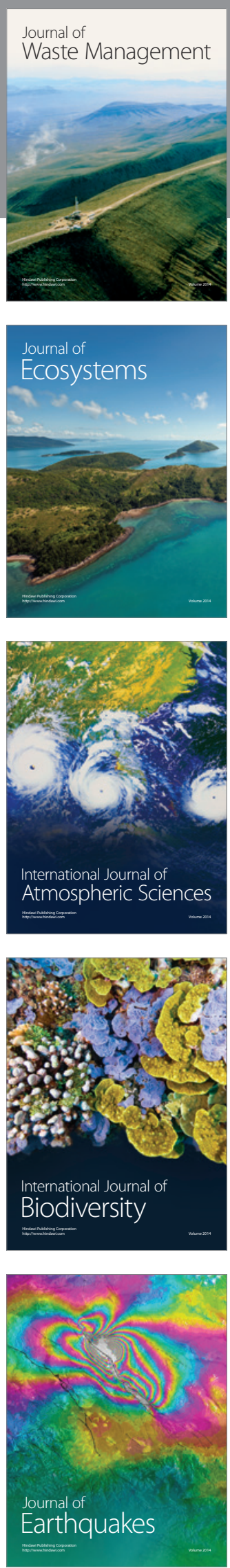
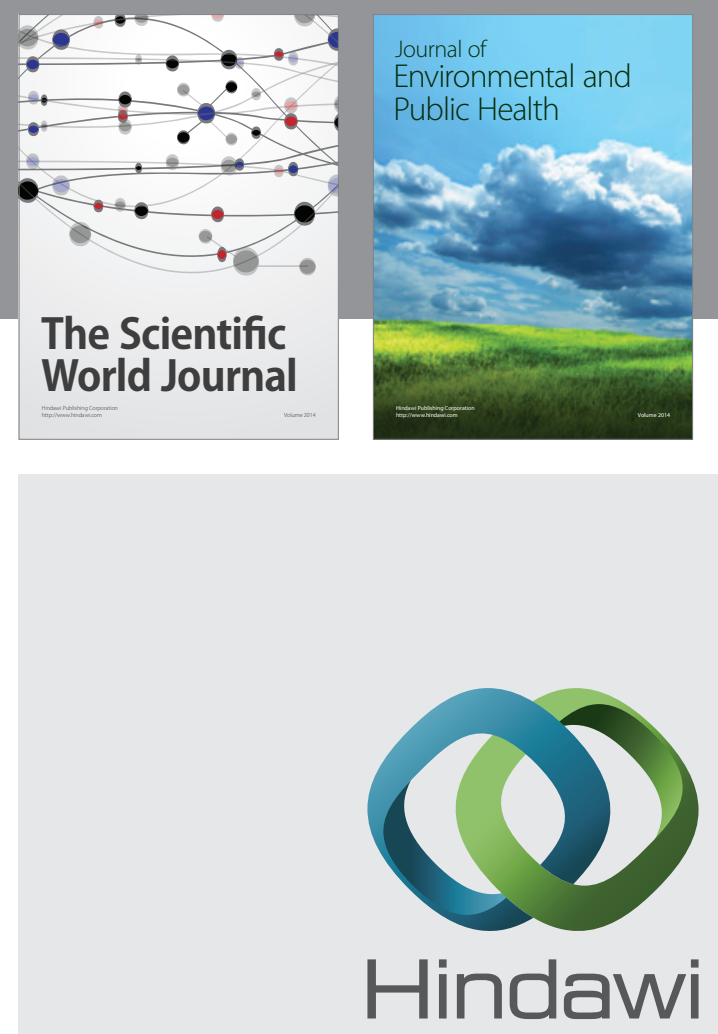

Submit your manuscripts at

http://www.hindawi.com
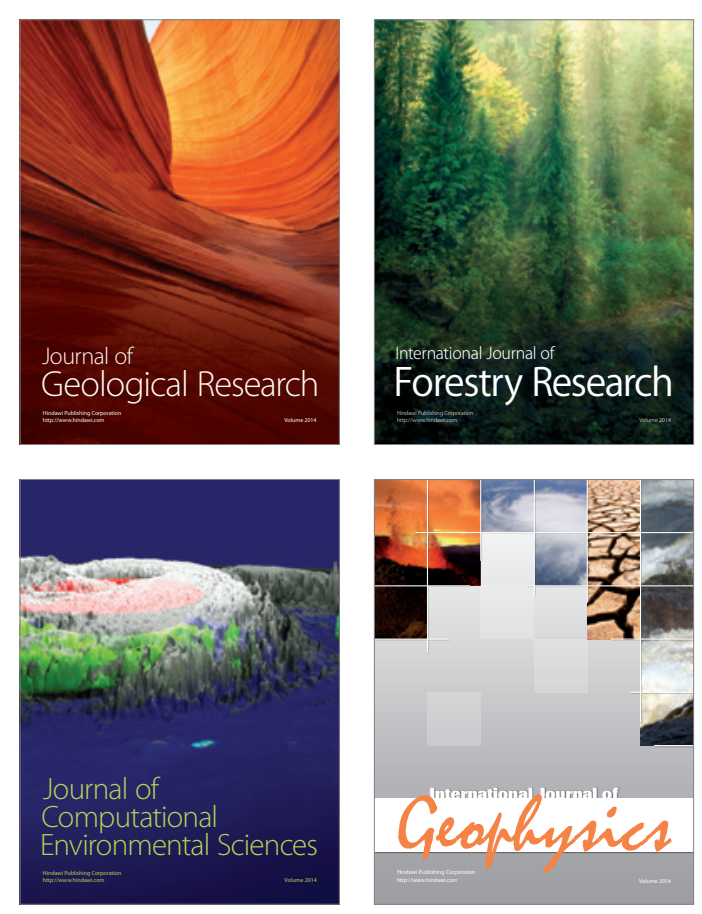
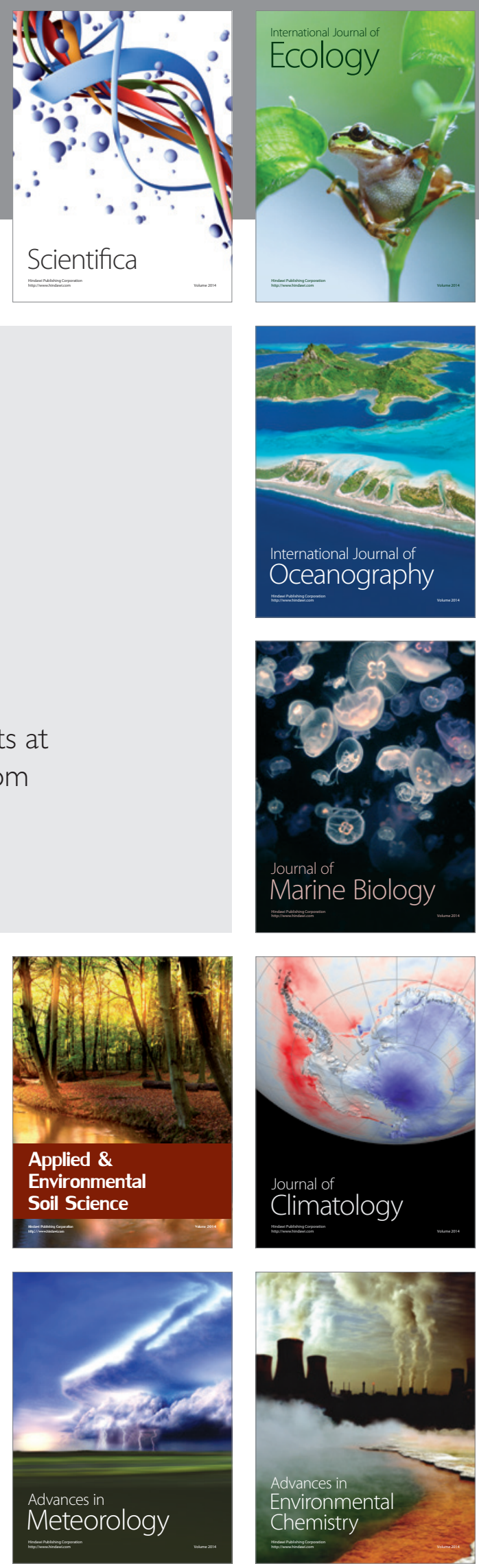